\title{
Use of genotyping-by-sequencing to determine the genetic structure in the medicinal plant chamomile, and to identify flowering time and alpha-bisabolol associated SNP-loci by genome-wide association mapping
}

Lars-Gernot Otto ${ }^{1 *}\left(\mathbb{D}\right.$, Prodyut Mondal ${ }^{2}$, Jonathan Brassac ${ }^{1}$, Susanne Preiss ${ }^{2}$, Jörg Degenhardt ${ }^{2}$, Sang $\mathrm{He}^{3}$, Jochen Christoph Reif ${ }^{3}$ and Timothy Francis Sharbel ${ }^{1,4}$

\begin{abstract}
Background: Chamomile (Matricaria recutita L.) has a long history of use in herbal medicine with various applications, and the flower heads contain numerous secondary metabolites which are medicinally active.

In the major crop plants, next generation sequencing (NGS) approaches are intensely applied to exploit genetic resources, to develop genomic resources and to enhance breeding. Here, genotyping-by-sequencing (GBS) has been used in the non-model medicinal plant chamomile to evaluate the genetic structure of the cultivated varieties/populations, and to perform genome wide association study (GWAS) focusing on genes with large effect on flowering time and the medicinally important alpha-bisabolol content.

Results: GBS analysis allowed the identification of 6495 high-quality SNP-markers in our panel of 91 M. recutita plants from 33 origins (2-4 genotypes each) and $4 \mathrm{M}$. discoidea plants as outgroup, grown in the greenhouse in Gatersleben, Germany. M. recutita proved to be clearly distinct from the outgroup, as was demonstrated by different cluster and principal coordinate analyses using the SNP-markers. Chamomile genotypes from the same origin were mostly genetically similar. Model-based cluster analysis revealed one large group of tetraploid genotypes with low genetic differentiation including 39 plants from 14 origins. Tetraploids tended to display lower genetic diversity than diploids, probably reflecting their origin by artificial polyploidisation from only a limited set of genetic backgrounds.

Analyses of flowering time demonstrated that diploids generally flowered earlier than tetraploids, and the analysis of alpha-bisabolol identified several tetraploid genotypes with a high content. GWAS identified highly significant $(P<0.01)$ SNPs for flowering time (9) and alpha-bisabolol (71). One sequence harbouring SNPs associated with flowering time was described to play a role in self-pollination in Arabidopsis thaliana, whereas four sequences harbouring SNPs associated with alpha-bisabolol were identified to be involved in plant biotic and abiotic stress response in various plants species.

(Continued on next page)
\end{abstract}

\footnotetext{
* Correspondence: ottolg@web.de

1Apomixis Research Group, Department Plant Breeding Research, Leibniz

Institute of Plant Genetics and Crop Plant Research (IPK), Corrensstrasse 3,

D-06466 Seeland OT Gatersleben, Germany

Full list of author information is available at the end of the article
} 
(Continued from previous page)

Conclusions: The first genomic resource for future applications to enhance breeding in chamomile was created, andanalyses of diversity will facilitate the exploitation of these genetic resources. The GWAS data pave the way for future research towards the genetics underlying important traits in chamomile, the identification of marker-trait associations, and development of reliable markers for practical breeding.

Keywords: Matricaria recutita, Chamomile, Medicinal and aromatic plant (MAP), Genetic diversity, Genome-wide association study (GWAS), Bisabolol, Genetic resources, Genotyping by sequencing (GBS), Single nucleotide polymorphism (SNP), Structure

\section{Background}

German Chamomile (Matricaria recutita L. syn. Chamomilla recutita (L.) Rauschert; from hereon chamomile) is described to be native to the Near East and SouthSoutheast Europe [1] and is grown in many temperate regions of the world. As already mentioned by Hippocrates (fifth century BC, [2]), it has a long history of use in herbal medicine, with applications in gastrointestinal diseases, treatment of infections and inflammatory diseases of the skin, and respiratory problems. The flower heads contain medicinal compounds, and are either used dried (e.g. tea) or the essential oils are extracted. Chamomile has numerous secondary metabolites which are medicinally active, including the terpenes alpha-bisabolol (syn. Levomenol) and its derivates (bisaboloids), matricine/ chamazulene, further terpenes, and several flavonoids [2].

Chamomile is mainly outcrossing [3, 4], and as most chamomile varieties are rather landraces, they display a high degree of phenotypic variability reflecting that of natural populations [5], from which they were isolated. Whereas wild populations of chamomile are diploid, agronomically cultivated varieties are either diploid or artificially generated tetraploid, the latter of which have larger flower heads and higher 1000-seed weight [6]. Genetic diversity in chamomile was evaluated in a few studies using a variety of different genetic markers (summarized in [7]), including AFLP [8], RAPD [8, 9] and ISSR [10]. Nextgeneration sequencing (NGS) approaches have been successfully used for the analysis and exploitation of genetic and genomic resources in crop plant breeding, including rapeseed, soybean, barley, or maize, e.g. [11, 12]. One NGS approach, genotyping by sequencing (GBS), has been widely used in many crop plants (e.g. [13-18]), is highly reproducible [13] and reduces genome complexity with restriction enzymes, thus, lowering costs. In contrast, the use of NGS / GBS for the amelioration of medicinal and aromatic plant breeding is relatively underexploited. An NGS approach has not yet been described for the nonmodel plant species chamomile.

In our work, we applied GBS to a set of chamomile origins (varieties, populations, accessions) to identify genome-wide, high quality single nucleotide polymorphisms (SNPs), to estimate genetic diversity and to reveal genetic structure within our cultivated chamomile germplasm collection. Therefore this is the first study reporting the generation and use of SNP markers in chamomile. We furthermore phenotyped the plants for flowering time (FT) and the content of bisaboloids by gas chromatography-mass spectrometry (GC-MS). Using phenotyping and genotyping data, an association study was performed to identify SNPs associated with FT and bisaboloids content, and to search for possible candidate genes underlying FT and the production of the medicinally-important compound alpha-bisabolol. In comparison to other marker platforms like AFLP or RAPD, the high marker density of genome-wide SNPs generated by GBS increases the probability of identifying markers closely linked to genes of interest. The resulting data provide a basis to enhance breeding in chamomile.

\section{Methods \\ Plant material}

Ninety one genotypes, representing 2-4 genotypes each from 33 origins of $M$. recutita L., and an additional 4 genotypes from $2 \mathrm{M}$. discoidea DC accessions as outgroup, were included in the analysis (Table 1). The focus of the study on cultivated chamomile, mainly encompassing origins from all over Europe, but also including some locations outside of Europe.

For the purpose of this study, we define an origin as either a registered variety, a gene bank accession, a cultivated or wild population of chamomile. The term population applies to a wild natural population as well as to a cultivated one selected for breeding or agriculture. Genotype refers to a genetically individual plant.

\section{Plant cultivation and ploidy analysis}

Seeds were sown in the greenhouse on the 16th July 2014, and seedlings were individually transplanted into single pots $(14 \mathrm{~cm}$ diameter) after reaching the 20-leaf stage. Between 2 to 4 genotypes per origin were selected for the subsequent analysis, with a focus on elite varieties/ populations (4 genotypes each). Plant ploidy was determined by flow-cytometry according to Otto et al. [19] at the 10- to 20-leaf stage. 
Table 1 Origin name, genotype code, described geographical origin and source of the investigated plants

\begin{tabular}{|c|c|c|c|c|}
\hline Origin $^{a}$ & Genotype code & Geographic origin & Geographic region $^{b}$ & Source \\
\hline Manzana1 & $002 \_02^{c}, 002 \_04^{c}$ & Germany & 1 & Pharmaplant GmbH \\
\hline Bodegold & $003 \_01^{c}, 003 \_02^{c}, 003 \_03^{c}, 003 \_04^{c}$ & Germany & 1 & Pharmasaat $\mathrm{GmbH}$ \\
\hline Camoflora & $004 \_01^{c}, 004 \_03^{c}, 004 \_04^{c}$ & Germany & 1 & Pharmaplant GmbH \\
\hline Lutea & $005 \_01^{c}, 005 \_02^{c}, 005 \_03^{c}, 005 \_04^{c}$ & Slovakia & 2 & Pharmaplant GmbH \\
\hline Zloty Lan & $006 \_01^{c}, 006 \_02,006 \_03^{c}, 006 \_04^{c}$ & Poland & 2 & Pharmasaat GmbH \\
\hline Goral & $007 \_01^{c}, 007 \_02^{c}, 007 \_03^{c}, 007 \_04$ & Slovakia & 2 & Pharmasaat GmbH \\
\hline Bohemia & $008 \_02^{c}, 008 \_04^{c}, 008 \_05^{c}$ & Czech Republic & 2 & Semo \\
\hline Promyk & 009_01,009_02 ${ }^{c}, 009 \_03^{c}$ & Poland & 2 & Pharmaplant GmbH \\
\hline Argenmilla & $010 \_02^{c}, 010 \_03,010 \_06^{c}$ & Argentina & 5 & Pharmaplant GmbH \\
\hline trade $\mathrm{B}+\mathrm{T}$ & $011{ }^{0} 01^{c}, 011 \_04^{c}, 011 \_05^{c}$ & France & 1 & B and T World Seeds \\
\hline trade FStM & 013_04, 013_06 & France & 1 & Ferme de Saint Marthe \\
\hline trade PNOS & $014 \_04^{c}, 014 \_05^{c}$ & Poland & 2 & PNOS Poland \\
\hline trade Kiepenkerl & $016 \_02^{c}, 016 \_04^{c}$ & Germany & 1 & Kiepenkerl, Bruno Nebelung GmbH \\
\hline trade Italy 6 & $019 \_01^{c}, 019 \_03^{c}$ & Italy & 4 & Flortis \\
\hline pop England 1 & 020_01, 020_04 & England & 1 & Pharmaplant GmbH \\
\hline trade Garafarm & $021 \_02^{c}, 021 \_03^{c}, 021 \_05^{c}$ & Hungary & 2 & Garafarm \\
\hline Margaritar & $0221^{c}, 022 \_02^{c}, 022 \_04^{c}, 022 \_06^{c}$ & Romania & 3 & Pharmaplant GmbH \\
\hline trade Agbina & $023 \_01^{c}, 023 \_02^{c}, 023 \_03^{c}$ & Russia & 5 & Agbina \\
\hline Lazur & $024 \_02^{c}, 024 \_03^{c}, 024 \_05^{c}, 024 \_07^{c}$ & Bulgaria & 3 & Pharmaplant GmbH \\
\hline Germania & $026 \_01^{c}, 026 \_02,026 \_04^{c}, 026 \_05^{c}$ & Egypt & 4 & N.L. Chrestensen \\
\hline trade USA & $027 \_02^{c}, 027 \_03,027 \_04^{c}$ & USA & 5 & Pharmaplant GmbH \\
\hline pop Croatia & $029 \_03^{c}, 029 \_04^{c}, 029 \_07^{c}$ & Kroatien & 3 & Pharmaplant GmbH \\
\hline trade Italy 5 & $032 \_01^{c}, 032 \_04^{c}, 032 \_05^{c}$ & Italy & 4 & Flortis \\
\hline trade Italy 4 & 033_03, $033 \_05^{c}$ & Italy & 4 & Plantania \\
\hline pop Germany 1 & $064 \_01^{c}, 064 \_03^{c}$ & Germany & 1 & Genebank Gatersleben MAT 2 \\
\hline Pohorelicky Velkokvety & $066 \_04^{c}, 066 \_07^{c}$ & Czech Republic & 2 & Genebank Gatersleben MAT 15 \\
\hline pop Bulgaria 1 & 067_02, 067_04 & Bulgaria & 3 & Genebank Gatersleben MAT 16 \\
\hline Krajovy & $515 \_01^{c}, 515 \_04$ & Slovakia & 2 & Genebank Gatersleben MAT 10 \\
\hline pop North Korea 1 & 516_01, 516_04, 516_07c & North Korea & 5 & Genebank Gatersleben MAT 19 \\
\hline Bona & 715_04, $715 \_06$ & Slovakia & 2 & Vet.med. University of Vienna \\
\hline Manzana2 & 717_03, $717 \_04^{c}$ & Austria & 1 & Vet.med. University of Vienna \\
\hline pop England 2 & 721_03', 721_04 & England & 1 & coll. R. Pickering \\
\hline pop England 3 & 722_03, $722 \_04^{c}$ & England & 1 & coll. R. Pickering \\
\hline M. discoidea 1 & 701_01 & Germany & 1 & $\begin{array}{l}\text { Loki-Schmidt Genbank Osnabrück, } \\
\text { Inv.-Nr:09-00-0145 }\end{array}$ \\
\hline M. discoidea 2 & MD1_04, MD1_05, MD1_06 ${ }^{c}$ & Germany & 1 & $\begin{array}{l}\text { Loki-Schmidt Genbank Osnabrück, } \\
\text { Inv.-Nr:04-00-0280 }\end{array}$ \\
\hline
\end{tabular}

OOrigins (variety, accession, wild and cultivated population) are named, if applicable, with the same or consecutive numbers as in Otto et al. [19] (e.g. trade Italy 6) ${ }^{\mathrm{b}}$ Based upon the climate from each origin, plants were classified into 5 geographic groups (according to Kottek et al. [76]): (1) middle-west Europe (2) middle-east Europe: (3) south-east Europe: (4) Mediterranean (5) remainder: USA, Argentina, Russia, North-Korea

${ }^{c}$ Analysis of chemical compounds was performed

Plants were randomized in the greenhouse, organized in a block of plants of $6 \times 16$ plants, and grown until the 31st of January 2015 under natural light conditions (short day conditions, with day / night temperatures of $17-21^{\circ} \mathrm{C}(12 \mathrm{~h}) / 14-$ $\left.19^{\circ} \mathrm{C}(12 \mathrm{~h})\right)$ and from February 2015 until the end of April
2015 under additional light for $16 \mathrm{~h}$ (long day conditions, MASTER Agro 400 W E40 1SL Na-bulb lamp, $2000 \mathrm{~K}$ colour temperature, Royal Philips N.V. Netherlands) with day / night temperatures of $18-21{ }^{\circ} \mathrm{C}(12 \mathrm{~h}) / 15-17{ }^{\circ} \mathrm{C}(12 \mathrm{~h})$. Flowering time (FT) was measured as days after sowing (DAS). 
Analysis of chemical compounds by gas chromatography mass spectrometry (GC-MS)

The content (peak areas) of bisaboloids (terpenoids), namely bisabolol oxide $\mathrm{B}$, bisabolon oxide $\mathrm{A}$, alphabisabolol, and bisabolol oxide A, were analysed by gas chromatography for 80 samples (76 from $M$. recutita and 4 from $M$. discoidea). The content of the chemical compounds was determined for each genotype in a sample of pooled flower heads, where flower heads were harvested after the first 2 circles of florets started flowering, scored as the flowering time until maximum half of the florets were flowering. All plants were grown and processed equally. Samples were immediately frozen in liquid nitrogen and stored at $-80^{\circ} \mathrm{C}$ until further analysis to prevent the oxidation of alpha-bisabolol.

The analysis by GC-MS was done with modifications according to Köllner et al. [20] and Irmisch et al. [21]. For each sample, the finely ground powder on liquid nitrogen of 80 to $100 \mathrm{mg}$ material from 5 flower heads was used. For each pulverized sample 200-400 $\mu \mathrm{l}$ of n-hexane was added, followed by overnight incubation with shaking at $25{ }^{\circ} \mathrm{C}$. A total of $100 \mu \mathrm{l}$ was transferred to a clean microtube fitted for GC vials. Terpene analysis was carried out with a gas chromatograph (GC 2010, Shimadzu, Duisburg, Germany) equipped with a splitless injector (injector temperature, $220{ }^{\circ} \mathrm{C}$; injection volume, $1 \mu \mathrm{l}$ ) and coupled to a quadrupole mass selective detector (Shimadzu). $\mathrm{H}_{2}$ was used as carrier gas at a flow rate of $1 \mathrm{ml} \mathrm{min-}^{1}$. Samples were analysed on a Supreme- $5 \mathrm{~ms}$ column $(30 \mathrm{~m}$ length $\times 0.25 \mathrm{~mm}$ inner diameter $\times 0.25 \mu \mathrm{m}$ film thickness, Chromatographie Service GmbH, Germany). The coupled mass spectrometer was operated with a transfer line temperature of $230{ }^{\circ} \mathrm{C}$, a source temperature of $230{ }^{\circ} \mathrm{C}$, a quadrupole temperature of $150{ }^{\circ} \mathrm{C}$, an ionization potential of $70 \mathrm{eV}$ and a scan range of 50-350 amu.

A flame ionization detector (FID) was used for the quantification of the compounds ( $\mu \mathrm{g} / \mathrm{g}$ of fresh weight), and operated at $250{ }^{\circ} \mathrm{C}$. Compounds were identified by comparison of retention times and mass spectra to those of authentic reference substances obtained from SigmaAldrich (Steinheim, Germany), Roth (Karlsruhe, Germany), or by reference spectra in the Wiley and Shimadzu libraries [22].

\section{DNA extraction and genotyping-by-sequencing (GBS)}

DNA was isolated from the 95 samples according to the manufacturer's instruction using the Agencourt Chloropure kit (Agencourt Bioscience Corp., Beverly, Massachusetts, USA). After isolation the DNA was analysed on a 1.3\% Agarose gel (Bio\&SELL Universal-Agarose), and the DNA concentration was determined relative to a DNA standard. DNA dissolved in TE buffer was shipped to the Cornell University Biotechnology Resource Center (BRC, Cornell, USA) for GBS analysis.
Sample preparation and sequencing was performed at the BRC using a protocol modified from Elshire et al. [3] (http://www.biotech.cornell.edu/brc/genomics-facility) using the enzyme ApeKI for digestion. GBS libraries constructed were sequenced in the BRC Genomics Facility on the Illumina HiSeq 2000/2500 (100 bp, single-end reads).

\section{Sequencing data analysis and SNP detection}

In the absence of a reference genome, the assembly was done de novo. The $156 \times 10^{6}$ barcoded reads from the 95 samples (genotypes) were demultiplexed, trimmed for restriction site and barcode, filtered and clustered using the software pipeline pyRAD v. 3.0 [23]. If not described differently, the default settings were used. The 4 samples from $M$. discoidea were assigned as outgroup, with the 91 remaining samples also defined as threshold $(n=91)$ for the maximum number of individuals with a shared heterozygous site to account for the high proportion of polyploid samples and the outcrossing nature of $M$. recutita. The minimal number of samples per locus was set to 75 , i.e. 75 from 91 samples having data at a particular locus, the parameter for the clustering threshold of reads within and between individuals was set to 0.88 , and filtering for barcodes, adapters and cut sites was done strictly setting value "2". The maximum ploidy level was appointed as tetraploid.

Using the above criteria, the pyRAD pipeline filtered and called 6495 SNPs from the $91 \mathrm{M}$. recutita genotypes.

\section{Analysis of the genetic diversity and genetic structure}

The genetic diversity and structure of cultivated chamomile was analysed with the filtered 6495 high-quality SNPs using the admixture model of STRUCTURE 2.3.4 [24-26]. The outgroup (4 genotypes from $M$. discoidea) was excluded from the analysis, since $M$. discoidea was clearly different from $M$. recutita. Ten independent analyses with K (number of clusters) ranging from 1 to 15 with 15,000 iterations as burn-in were performed followed by 50,000 supplementary Markov Chain Monte Carlo (MCMC) iterations. The optimal $\mathrm{K}$ was obtained according to Evanno et al. [27] using STRUCTURE Harvester [28]. For $\mathrm{K}=3$ and $\mathrm{K}=7$, an additional 10 independent analyses with 25,000 iterations as burn-in followed by 100,000 supplementary MCMC iterations were done and used for further analysis. The burn-in length was assessed by monitoring the parameters. CLUMPP v 1.1.2 [29] was used to align the results of individual runs (Greedy algorithm).

The allele frequencies were assumed to be correlated between the origins of chamomile rather than independent [25], as chamomile is a mainly outcrossing species whose seeds are exchanged for cultivation and breeding between regions, and thus the investigated populations / origins can share similar allele frequencies [25]. The 
admixture model was used, since it is more general and does not assume each individual to belong to a single cluster [26]. The value for lambda (allele frequencies parameter) was set to 0.3 after lambda was estimated in STRUCTURE. Otherwise, the default settings of STRUCTURE were used.

Additionally, the supermatrix of concatenated sequences, 682,699 bp long, was used to compute a phylogenetic tree. The neighbor joining method [30] with 100 bootstrap and keeping nodes above $75 \%$ was used to obtain a consensus phylogenetic tree with Geneious v.10.0.9 (https:// www.geneious.com, [31]). To validate the results from the neighbor-joining and STRUCTURE analysis, principal coordinate analysis $(\mathrm{PCoA})$ was done.

\section{Analysis of phenotype-genotype associations}

To obtain markers for GWAS analysis (genome wide association studies), the full sequences (contigs) identified by the pyRAD pipeline as harbouring all the 6495 SNPs of the STRUCTURE analysis were used to detect 44,468 polymorphic markers within a set incorporating all 95 genotypes. Due to the lack of genetic or physical map, the minor number of missing profiles were imputed by means of Random Forest algorithm [32] through R package "missForest" [33]. Quality control was applied such that markers with call rates less than $90 \%$ were excluded $[34,35]$. In the end, out of the 44,468 polymorphic markers 16,972 markers, including 16,333 biallelic and 639 multiallelic, were available for subsequent GWAS. Since the single results in GWAS were subsequently evaluated (including consideration of the $p$-values and $r^{2}$-values), different criteria for SNP filtering were applied than for the genetic structure analysis so that more SNPs could be used as basic data for the GWAS.

Considering the lack of phenotyping replicates here, estimating the heritability was not feasible. Nevertheless, genomic heritability $[36,37]$ is a well-suited surrogate for the heritability. We estimated genomic heritability via a replicated (20x) 5-fold cross validation, as the square of average correlation from the 20 replications comparing predicted genotypic values and phenotypic values of respective traits.

GWAS was performed with the R package "rrBLUP" [38] using phenotypic data and the 16,972 markers obtained. The kinship matrix was estimated with a G matrix [39] using 5768 markers (out of the total 16,972 markers) whose minor allele frequency was above 0.05 . The final significance test for each marker/allele was accomplished using F-test in "rrBLUP". The percentage of phenotypic variance explaining each significant marker was estimated via $R^{2}$ by fitting a regression between phenotypes and marker profiles, as implemented in $\mathrm{R}$ using the function "lm".

The DNA sequences containing highly significant markers as identified by GWAS were annotated using firstly BLAST (blastn and tblastx; [40, 41], http://blast. ncbi.nlm.nih.gov/Blast.cgi) against the NCBI plant genomes nucleotide collection of flowering plants data using the discontiguous megablast algorithm. Mapping and annotation of the BLAST-results were performed using Blast2GO 4.0.2 and default settings [42-45]. Additionally, blastn against the Helianthus annuus (sunflower) XRQ genome assembly was done at https://www.heliagene.org/HanXRQ-SUNRISE/ [46], since sunflower is the closest related species with a sequenced genome available, belonging together with chamomile in the Asteraceae. Local BLAST analysis was done with CLC Genomics Workbench 8.5 (QIAGEN Aarhus A/S).

\section{Results}

Analysis of genetic structure reveals less genetic diversity for tetraploid than for diploid chamomile origins

As expected, the 4 genotypes of $M$. discoidea (outgroup) were clearly genetically separated from $M$. recutita (see Fig. 1, Additional file 1: Fig. S1 and Additional file 2: Fig. S2), and were thus excluded from further analyses. Using STRUCTURE, the optimal numbers of clusters (k) that described the population structure of the investigated chamomile were determined as 3 and 7 (Additional file 3: Fig. S3) for the main (Additional file 4: Fig. S4) and more detailed substructures (Fig. 2, Additional file 5: Table S1), respectively. Although the allele frequencies were assumed to be correlated between the origins of chamomile, STRUCTURE was nonetheless additionally run with the setting of independent allele frequencies, which lead to far less population structure differentiation (as expected and described by Falush et al. [25]), but did not significantly differ from the outcome of the analysis with correlated allele frequencies (Additional file 6: Fig. S5). In general, the STRUCTURE analyses demonstrated that the single plants of an origin were genetically similar, with moderate exceptions occurring (Fig. 2, e.g. $005=$ 'Lutea' or $010=$ 'Argenmilla').

The plants characterized by 1 or 2 main STRUCTURE clusters, i.e. having one or two STRUCTURE colours $>=9.5 \%$ (Fig. 2) were mostly tetraploids (average ploidy of the whole group close to tetraploid: Additional file 7: Fig. S6), whereas all plants except one with 3 to 5 different main STRUCTURE clusters $(>=9.5 \%)$ were diploid (Fig. 2, Additional file 7: Fig. S6). Except for one genotype ('Camoflora' 004_04) all tetraploids had only 1 or 2 main genetic clusters, whereas diploids showed far more genetic diversity (Fig. 2 and Table 2), although several origins of wild growing chamomile populations were also relatively homogenous $(020,064,721,722)$.

In particular, the 39 genotypes from 14 tetraploid origins (USA and throughout Europe) were genetically similar and homogenous, forming one large group (see Fig. 2, Additional file 8: Fig. S7: red coloured bars, Fig. 1: 




Fig. 1 Phylogenetic tree of $M$ recutita samples calculated with the neighbor-joining method. The tree derived from the supermatrix consisting of all concatenated sequences and was rooted with the outgroup M. discoidea (MD1 and 701). The long branch leading to the outgroup was arbitrarily shortened for clarity. Bootstrap values (bs) of the clades above 75 are indicated close to the nodes

parenthesis " $4 \times$ ", Additional file 1: Fig. S1: red coloured dots and Additional file 9: Fig. S8a). Furthermore, 9 tetraploid genotypes ('Lutea' $=005$, 'Zloty Lan' $=006$ and one genotype 'Goral' = 007_01) and all four plants 'Manzana' (both origins 002 and 717) formed two additional groups. 'Manzana', like several other origins (e.g. an accession from North Korea (516), 'Camoflora' (004) and a genebank accession from Bulgaria (067)), was identified as being genetically different from most of the origins (Fig. 2). No clear connection between the genetic structure (clusters) and the geographic origin was apparent, i. e. no geographic differentiation could be identified (Fig. 2 and Additional file 9: Fig. S8b), even though the origins from Argentina (010) and North Korea (516) indeed seem to be a little bit more distinct (Additional file 9: Fig. S8b).

\section{Average flowering time for diploid chamomile is shorter than for tetraploids}

Diploid chamomile plants flowered significantly earlier than tetraploid ones (Fig. 3, Additional file 10: Table S2: average flowering time $201 \mathrm{~d}$ vs. $244 \mathrm{~d}$, t-test: $P=4.20 \times 10^{-5}$ ), and most of the plants (70 out of 78) flowered under long-day conditions, that is 200 DAS. Tetraploid plants showed a narrower range of FT than diploid ones (Fig. 3). In total only 8 genotypes and the $4 M$. discoidea plants as outgroup flowered under short-day conditions (Table 2: all three from Argenmilla (010), two out of three from "population Croatia" (029_03, 029_04), and one from each origin 'Bona' (715_04), 'Camoflora' (04_04), and NorthKorea (516_07)). All genotypes flowering under short-day conditions were diploid except for one tetraploid genotype ("04_04") from the variety 'Camoflora'. A PCoA-analysis revealed for most of these plants (except 715_04 and 04_04) clear differences to the later flowering ones (Additional file 9: Fig. S8c).

\section{The content of the bisaboloids was highly variable} between the genotypes

Large differences in the content of single bisaboloids were measured between the genotypes and origins, with single genotypes tending to be rich in only one of the four bisaboloids, i.e. plants showing a high content of alpha-bisabolol often had a low content of bisabolol oxide A and bisabolon oxide A (Fig. 4, Table 2). The plants from the outgroup $M$. discoidea had low contents of bisaboloids, only bisabolon oxide A was present to some extent (Fig. 4). 




In total, 52 plants out of 80 showed no detectable content of alpha-bisabolol. The plants with high levels of the medicinal important substance bisabolol Fig. 4) were the 4 genotypes from 'Manzana' (002_02, 002_04, 717_03, 717_04) and the genetically defined group (see above and Fig. 2) consisting of 'Camoflora,'Lutea' and one genotype from 'Goral' (007_01). The alpha-bisabolol rich genotypes were characterized by two main STRUCTURE clusters each $(>=9.5 \%$ share of each genetic cluster, compare Table 2 and Fig. 2).
Genome-wide association study (GWAS) identified significantly associated SNP-markers for the traits flowering time and alpha-bisabolol

The estimated genomic heritabilities for the traits flowering time and content of alpha-bisabolol were above 0.4 (0.48 and 0.40 respectively, Fig. 5, Additional file 11: Table S3), while that for the content of bisabololoxide B, bisabolone oxide $\mathrm{A}$ and bisabololoxide A were clearly lower (0.01; 0.01; 0.14, Fig. 5, Additional file 11: Table S3). Thus, genome-wide association studies were performed 
Table 2 Ploidy level, flowering time (FT) and quantity of bisaboloids $(\mu \mathrm{g} / \mathrm{g})$ for the investigated plants

\begin{tabular}{|c|c|c|c|c|c|c|c|}
\hline Origin & Genotype & ploidy level $^{a}$ & $\mathrm{FT}^{\mathrm{b}}$ & Bisabolol oxide B & Bisabolon oxide A & alpha-Bisabolol & Bisabolol oxide A \\
\hline Manzana1 & 002_02 & $4 x$ & 230 & 0 & 0 & 400.22 & 3.17 \\
\hline Manzana1 & 002_04 & $4 \times$ & 232 & 0 & 0 & 735.82 & 0 \\
\hline Bodegold & 003_01 & $2 x$ & 223 & 6.15 & 50.3 & 11.17 & 119.57 \\
\hline Bodegold & 003_02 & $2 x$ & 236 & 285.35 & 0 & 0 & 190.8 \\
\hline Bodegold & 003_03 & $4 x$ & 285 & 0 & 0 & 0 & 6.2 \\
\hline Bodegold & 003_04 & $2 x$ & 246 & 8.62 & 27.3 & 0 & 145.42 \\
\hline Camoflora & 004_01 & $2 x$ & 236 & 100.82 & 44.92 & 0 & 115.37 \\
\hline Camoflora & 004_03 & $2 x$ & 230 & 12.12 & 0 & 0 & 18.67 \\
\hline Camoflora & 004_04 & $4 \times$ & 119 & 35.15 & 0 & 0 & 156.47 \\
\hline Lutea & 005_01 & $4 \times$ & 239 & 859.75 & 0 & 181.1 & 21.45 \\
\hline Lutea & 005_02 & $4 \times$ & 244 & 23.3 & 0 & 506.02 & 0 \\
\hline Lutea & 005_03 & $4 x$ & 239 & 15.37 & 0 & 811.2 & 0 \\
\hline Lutea & 005_04 & $4 x$ & 244 & 63.8 & 20.12 & 9.3 & 16.8 \\
\hline Zloty Lan & 006_01 & $4 \times$ & 254 & 6.3 & 0 & 353.15 & 0 \\
\hline Zloty Lan & 006_02 & $4 x$ & NA & NA & NA & NA & NA \\
\hline Zloty Lan & 006_03 & $4 \times$ & 278 & 490.95 & 5.12 & 186.72 & 0 \\
\hline Zloty Lan & 006_04 & $4 x$ & 239 & 378.15 & 24.65 & 0 & 89 \\
\hline Goral & 007_01 & $4 \times$ & 232 & 970.9 & 0 & 144.02 & 23.67 \\
\hline Goral & 007_02 & $4 \times$ & 252 & 33.27 & 852.22 & 24.62 & 277.62 \\
\hline Goral & 007_03 & $4 \times$ & 246 & 848.27 & 0 & 2.47 & 25.77 \\
\hline Goral & 007_04 & $4 x$ & NA & NA & NA & NA & NA \\
\hline Bohemia & 008_02 & $4 x$ & 243 & 14.25 & 106.95 & 0 & 0 \\
\hline Bohemia & 008_04 & $4 \times$ & 257 & 37.4 & 43 & 0 & 9.3 \\
\hline Bohemia & 008_05 & $4 x$ & 236 & 200.52 & 351.6 & 0 & 0 \\
\hline Promyk & 009_01 & $2 x$ & NA & NA & NA & NA & NA \\
\hline Promyk & 009_02 & $2 x$ & 230 & 2.19 & 0 & 0 & 0 \\
\hline Promyk & 009_03 & $2 x$ & 239 & 382.27 & 0 & 0 & 7.5 \\
\hline Argenmilla & 010_02 & $2 x$ & 78 & 366.05 & 176.9 & 0 & 323.85 \\
\hline Argenmilla & 010_03 & $2 x$ & 78 & NA & NA & NA & NA \\
\hline Argenmilla & 010_06 & $2 x$ & 106 & 487.52 & 0 & 0 & 10.25 \\
\hline trade $B+T$ & 011_01 & $4 \times$ & 257 & 527.6 & 0 & 0 & 7.2 \\
\hline trade $B+T$ & 011_04 & $4 x$ & 254 & 69.62 & 0 & 0 & 72.12 \\
\hline trade $B+T$ & 011_05 & $4 \times$ & 254 & 239.95 & 35.12 & 0 & 0 \\
\hline trade FStM & 013_04 & $4 x$ & NA & NA & NA & NA & NA \\
\hline trade FStM & 013_06 & $4 x$ & 265 & 11.45 & 433.8 & 0 & 0 \\
\hline trade PNOS & 014_04 & $4 \times$ & 254 & 0 & 0 & 0 & 10.42 \\
\hline trade PNOS & 014_05 & $4 x$ & 252 & 18.45 & 0 & 14.95 & 128.1 \\
\hline trade Kiepenkerl & 016_02 & $4 x$ & 236 & 9.85 & 0 & 0 & 92.85 \\
\hline trade Kiepenkerl & 016_04 & $4 x$ & 243 & 90.87 & 0 & 0 & 59.67 \\
\hline trade Italy 6 & 019_01 & $4 \times$ & 236 & 14.17 & 0 & 0 & 134.47 \\
\hline trade Italy 6 & 019_03 & $4 \times$ & 265 & 293.37 & 0 & 48.65 & 3.4 \\
\hline pop England 1 & 020_01 & $2 x$ & NA & NA & NA & NA & NA \\
\hline pop England 1 & 020_04 & $2 x$ & NA & NA & NA & NA & NA \\
\hline trade Garafarm & 021_02 & $4 \times$ & 257 & 17.32 & 0 & 0 & 79.57 \\
\hline
\end{tabular}


Table 2 Ploidy level, flowering time (FT) and quantity of bisaboloids $(\mu \mathrm{g} / \mathrm{g})$ for the investigated plants (Continued)

\begin{tabular}{|c|c|c|c|c|c|c|c|}
\hline trade Garafarm & 021_03 & $4 x$ & 252 & 664.47 & 13.35 & 0 & 0 \\
\hline trade Garafarm & 021_05 & $>4 x^{c}$ & 236 & 127.75 & 0 & 0 & 133.8 \\
\hline Margaritar & 022_01 & $4 x$ & 246 & 478.2 & 10.55 & 3.92 & 7.2 \\
\hline Margaritar & 022_02 & $4 x$ & 243 & 165.32 & 49.22 & 35.1 & 0 \\
\hline Margaritar & 022_04 & $4 x$ & 246 & 159.25 & 2.2 & 0.32 & 0 \\
\hline Margaritar & 022_06 & $4 x$ & 246 & 13.9 & 0 & 0 & 0 \\
\hline trade Agbina & 023_01 & $4 \times$ & 239 & 17.62 & 0 & 0 & 122.1 \\
\hline trade Agbina & 023_02 & $4 x$ & 236 & 185.4 & 39.95 & 0 & 174.15 \\
\hline trade Agbina & 023_03 & $4 x$ & 230 & 35.45 & 48.32 & 0 & 0 \\
\hline Lazur & 024_02 & $4 \times$ & 243 & 20.77 & 0 & 0 & 218.77 \\
\hline Lazur & 024_03 & $4 \times$ & 247 & 650.7 & 0 & 0 & 14.05 \\
\hline Lazur & 024_05 & $4 x$ & 239 & 178.1 & 0 & 0 & 131.85 \\
\hline Lazur & 024_07 & $4 \times$ & 252 & 0 & 0 & 0.42 & 58.27 \\
\hline Germania & 026_01 & $2 x$ & 246 & 74.32 & 0 & 0 & 572.77 \\
\hline Germania & 026_02 & $2 x$ & NA & NA & NA & NA & NA \\
\hline Germania & 026_04 & $2 x$ & 259 & 12.72 & 31.22 & 0 & 162.07 \\
\hline Germania & 026_05 & $2 x$ & 236 & 922.9 & 0 & 0 & 32.4 \\
\hline trade USA & 027_02 & $4 x$ & 246 & 5.86 & 67.8 & 0 & 74.77 \\
\hline trade USA & 027_03 & $4 \times$ & 272 & NA & NA & NA & NA \\
\hline trade USA & 027_04 & $4 x$ & 252 & 133.95 & 147.7 & 0 & 0 \\
\hline pop Croatia & 029_03 & $2 x$ & 78 & 0.5 & 0 & 21.02 & 0 \\
\hline pop Croatia & 029_04 & $2 x$ & 83 & 3.5 & 0 & 0 & 56.75 \\
\hline pop Croatia & 029_07 & $2 x$ & 218 & 129.57 & 0 & 0 & 2.4 \\
\hline trade Italy 5 & 032_01 & $4 x$ & 236 & 131.27 & 0 & 0 & 0 \\
\hline trade Italy 5 & 032_04 & $4 \times$ & 239 & 152.35 & 0 & 0 & 164.05 \\
\hline trade Italy 5 & 032_05 & $4 x$ & 243 & 97.62 & 0 & 0 & 134.77 \\
\hline trade Italy 4 & 033_03 & $4 x$ & 239 & 732.62 & 28.3 & 3.52 & 13.47 \\
\hline trade Italy 4 & 033_05 & $4 x$ & 252 & 854.7 & 0 & 0 & 11.65 \\
\hline pop Germany 1 & 064_01 & $2 x$ & 236 & 31.52 & 98.65 & 2.92 & 124.45 \\
\hline pop Germany 1 & 064_03 & $2 x$ & 260 & 78.37 & 101.5 & 2.35 & 242.37 \\
\hline Pohorelicky Velkokvety & 066_04 & $2 x$ & 239 & 0 & 81.32 & 0 & 294.95 \\
\hline Pohorelicky Velkokvety & 066_07 & $2 x$ & 239 & 77.79 & 65.62 & 0 & 209.92 \\
\hline pop Bulgaria 1 & 067_02 & $2 x$ & NA & NA & NA & NA & NA \\
\hline pop Bulgaria 1 & 067_04 & $2 x$ & NA & NA & NA & NA & NA \\
\hline Krajovy & 515_01 & $2 x$ & 239 & 186.65 & 0 & 0 & 262.25 \\
\hline Krajovy & 515_04 & $2 x$ & NA & NA & NA & NA & NA \\
\hline pop North Korea 1 & 516_01 & $2 x$ & NA & NA & NA & NA & NA \\
\hline pop North Korea 1 & 516_04 & $2 x$ & NA & NA & NA & NA & NA \\
\hline pop North Korea 1 & 516_07 & $2 x$ & 146 & 0 & 337.35 & 0 & 0 \\
\hline Bona & 715_04 & $2 x$ & 106 & 0 & 0 & 19.87 & 0 \\
\hline Bona & 715_06 & $2 x$ & NA & NA & NA & NA & NA \\
\hline Manzana2 & 717_03 & $4 x$ & 236 & 0 & 0 & 165.1 & 0 \\
\hline Manzana2 & 717_04 & $4 x$ & 239 & 0 & 0 & 437.27 & 0 \\
\hline pop England 2 & 721_03 & $2 x$ & 239 & 17.65 & 0 & 0 & 192.92 \\
\hline pop England 2 & 721_04 & $2 x$ & 232 & 105.25 & 0 & 1.47 & 144.27 \\
\hline
\end{tabular}


Table 2 Ploidy level, flowering time (FT) and quantity of bisaboloids $(\mu \mathrm{g} / \mathrm{g})$ for the investigated plants (Continued)

\begin{tabular}{|c|c|c|c|c|c|c|c|}
\hline pop England 3 & 722_03 & $2 x$ & 244 & 52.32 & 0 & 0 & 0.85 \\
\hline pop England 3 & 722_04 & $2 x$ & 225 & 143.7 & 9.27 & 0 & 157.72 \\
\hline M. discoidea 1 & 701_01 & & 78 & 0 & 41.07 & 0 & 0 \\
\hline M. discoidea 2 & MD1_04 & & 78 & 0 & 79.35 & 4.92 & 1 \\
\hline M. discoidea 2 & MD1_05 & & 78 & 0 & 29.75 & 0 & 0 \\
\hline M. discoidea 2 & MD1_06 & & 78 & 0 & 29.87 & 1.15 & 0 \\
\hline
\end{tabular}

${ }^{a}$ measured between the 26th of August 2014 and the 03rd of September 2014

${ }^{b}$ measured as days after sowing (DAS) to the start of flowering: NA = no flowering (plant dead before flowering); 78-200 DAS: short day conditions; 201-260 DAS: long day conditions

cploidy slightly higher than tetraploid level (7\%), grouped within the tetraploid plants

for flowering time and alpha-bisabolol only, focusing on the two traits for which a high portion of the phenotypic variability can be explained genetically.

GWAS resulted in the identification of 9 SNPs located in 5 different sequences for flowering time (FT) and 72 SNPs located in 60 different sequences for alpha-bisabolol content, all of which were above the defined significance threshold 0.01 under Bonferroni correction (Additional file 12: Table S4). Three sequences $(2445,3029,4585)$ harboured more than one SNP associated with FT, and ten sequences $(256,1379,1998,2208,2380,2489,5681$, $6623,6440,6670)$ more than one SNP associated with alpha-bisabolol content.

\section{Flowering time (FT)}

The BLAST alignment $[40,41]$ of the 5 sequences harbouring significantly associated SNPs (Additional file 12: Table S4) against the NCBI nucleotide collection of flowering plants identified 2 sequences with significant hits to potential candidate genes (BLAST-score of $>=80$ with a sequence identity of $>=80 \%$ and an E-value $<1 \times 10^{-13}$ ) in multiple plant species. Both sequences harboured more than one significantly associated SNP: (1) "seq. 2445" with 2 SNPs: xyloglucan endotransglucosylase/hydrolase protein



Fig. 3 Flowering time $[d]$ for 27 diploid $(2 x)$ and 51 tetraploid (4x) M. recutita plants. Box-whisker-plots of days after sowing (DAS) when flowering started, for diploid and tetraploid plants. The quartiles 2 and 3 are drawn with the median in between them. The whiskers indicate the maximum and minimum values, whereas the dot in the middle represents the arithmetic mean (Additional file 10: Table S2) with significant alignments to 30 plant species; and (2) "seq. 4585" with 3 SNPs: uncharacterized protein with significant alignments to 9 plant species, and protein kinase / salt-induced $\mathrm{ABC} 1$ kinase below the BLAST aligment results threshold in 2 plant species (Additional file 13: Table S5). Xyloglucan endotransglucosylase/hydrolase is described to be involved in self-pollination in Arabidopsis thaliana [47].

BLAST aligment (megablast) of the FT associated sequences to the sunflower genome [46] yielded hits for 4 of the 5 sequences on different chromosomes (multiple hits on 6 chromosomes for "2445", single hits all in different chromosomes for "441", "3029" and "4585").

\section{Alpha-bisabolol content}

Out of the 60 sequences (contigs) associated with alpha-bisabolol content in our study (Additional file 12: Table S4), 31 could be aligned by BLAST against the NCBI nucleotide collection of flowering plants, of which 13 sequences achieved matches above the selected threshold (listed in Additional file 13: Table S5 together with the suggested functional role of the putative gene: BLAST-score of $>=80$ with a sequence identity of $>=75 \%$ and an E-value $<1.33 \times 10^{-13}$ ). For 12 of these 13 sequences specific gene products were described in multiple plant species (Additional file 13: Table S5).

Whereas 8 (sequences 3218, 3223, 3249, 4194, 6598, 6694) of the 12 sequences are involved in synthesis or regulation within universal pathways and associated ubiquitous proteins in many eukaryotes or plants (Additional file 13: Table S5), 4 sequences are described to play a role in plant biotic and abiotic stress response. Interestingly, one sequence (3223) is described to be involved both in basic function and in abiotic stress response ([48]: armadillo/beta-catenin repeat family proteins). Ascorbate peroxidase (722) responses are directly involved in the protection of plant cells against adverse environmental conditions [49], Glutamate receptor-like channels (1139) in plants are discussed to fulfill a function in response to an attack from pests and pathogens [50], and the chaperone protein ClpB1 (5721) is described to be a heat shock protein required for acclimation to high temperatures [51]. 


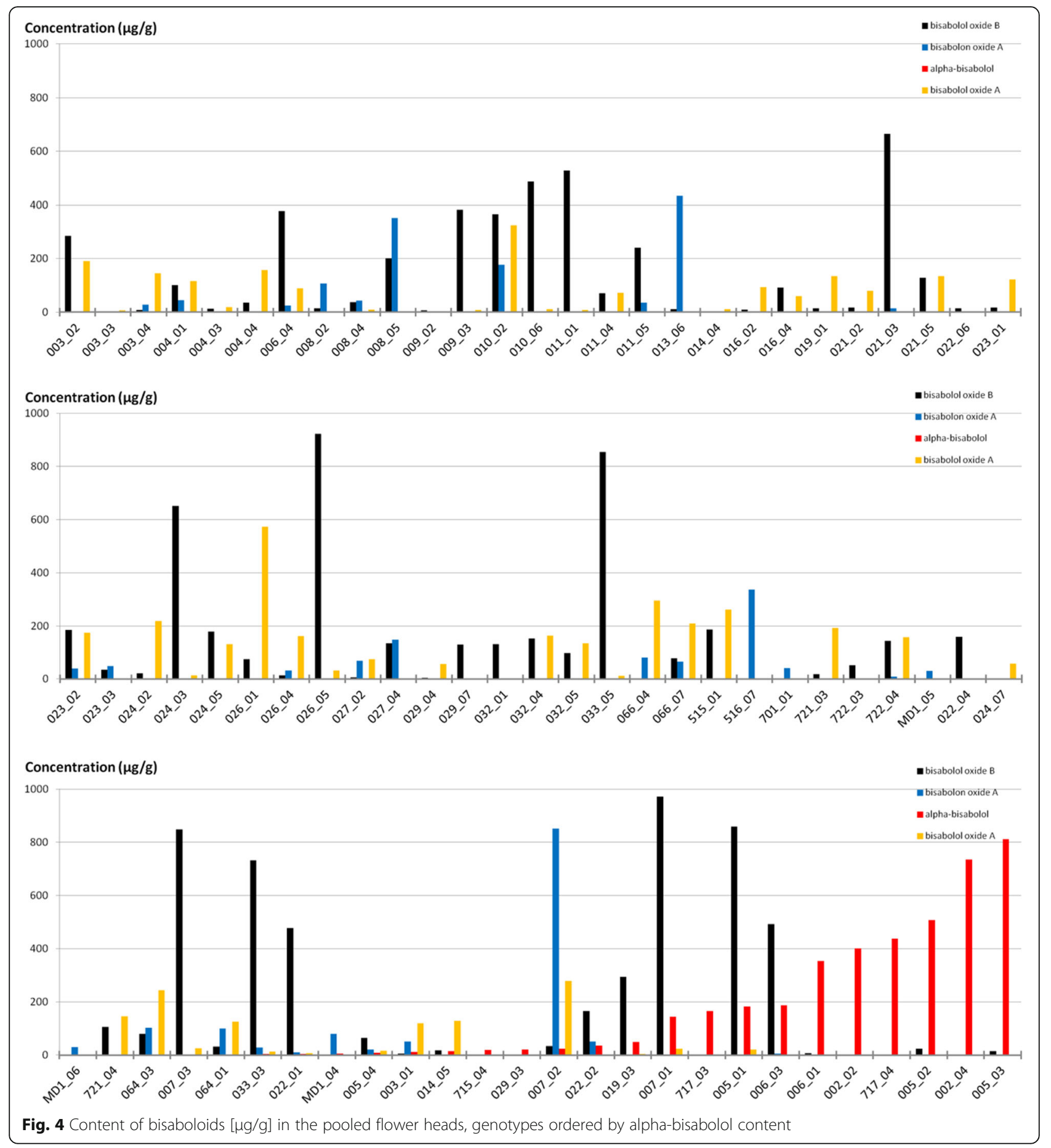

The last sequence (1998) is predicted to encode a nuclear fusion defective 4-like protein, which is described to be required for karyogamy during female gametophyte development and fertilization in Arabidopsis thaliana [52].

The BLAST aligment (megablast) of the 60 sequences associated with alpha-bisabolol content against the sunflower genome [46] yielded 35 matches above the threshold for the E-value of $10^{-3}$. 12 of the 13 sequences from the alignment to different plant genomes (Additional file 13: Table S5, except the microsatellite sequence "1379") were above the threshold value for the alignment against sunflower genome.

The 35 sequences with E-value above the threshold, were aligned to all 17 chromosomes of the sunflower genome, with minimum of 1 (chromosome 17) and maximum of 7 to 8 (chromosomes 8,10 and 13) sequences 


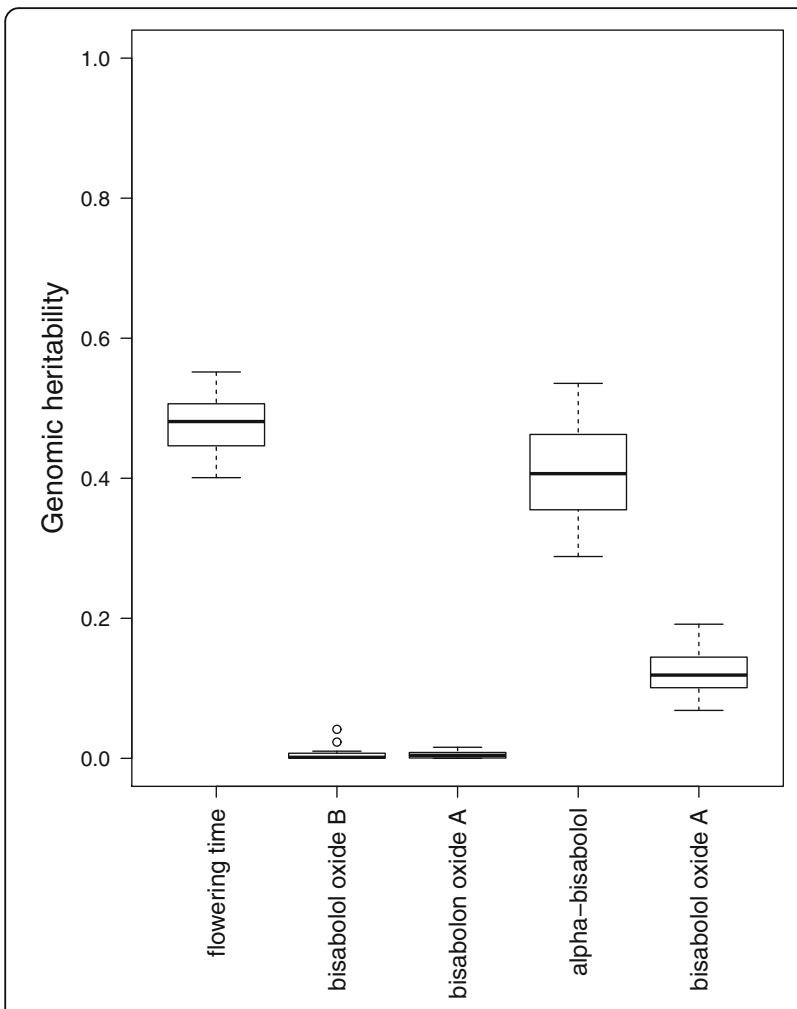

Fig. 5 Genomic heritability* for flowering time and content of the four bisaboloids. *The genomic heritability is given in a range between 0 and 1 (y-axis), and estimates how much of the observed phenotypic variation can be explained genetically. In the box-whisker-plot the quartiles 2 and 3 are drawn, with the median in between them. The whiskers indicate the maximum and minimum values (Additional file 11: Table S3)

per chromosome (Additional file 14: Table S6). Among these 35 sequences, 14 were aligned to only 1 sunflower chromosome, 10 to 2 different sunflower chromosomes, and the remaining 11 to multiple chromosomes, with sequences "4194" and " 5751 " both being aligned to 6 chromosomes. Ten sequences were aligned to multiple loci on the same chromosome. Tblastx gave more hits against the sunflower genome, but with higher E-value and only consisting of more multiple hits against the same chromosomes.

The sequences for which specific gene products in multiple plant species were identified (see above) were not concentrated on any of the sunflower chromosomes (Additional file 14: Table S6: sequence name written bold). Based on these data, no clustering of these 35 highly alpha-bisabolol associated sequences to single sunflower chromosomes could be observed.

Mapping by Blast2GO of the BLAST results to retrieve gene ontology terms for FT and alpha-bisabolol content achieved no matches. Thus, no functional annotation could be done.

\section{Discussion}

Rare autopolyploidization events are a potential cause for low genetic diversity of the cultivated tetraploid chamomile Tetraploid chamomile varieties were generated a very few times artificially by polyploidisation of diploid plants, as evidenced by the STRUCTURE analyses (Fig. 2). The large, genetically homogenous group of 14 tetraploid orgins, obtained from all over Europe, is likely to originate from the same polyploidised diploid genetic background, i.e. similar parental material, with minor genetic differences arising via selection and introgression during breeding. These data indicate that most of the high-performing tetraploid chamomile origins are genetically highly similar, and justify the demand to further broaden the diversity by including different germplasm in the future breeding process. Two smaller, genetically different groups of tetraploid origins with "extended" genetic background include plants with the highest alpha-bisabolol content (see below): (1) The tetraploid variety 'Manzana', which was generated from diploid 'Degumille' [53] and (2) the group containing 'Lutea,' 'Zloty Lan' and partly 'Goral'.

Two tetraploid genotypes (003_03 from 'Bodegold', 004_04 from 'Camoflora') were genetically diverse, each consisting of several STRUCTURE-clusters, although both were similar in "STRUCTURE fingerprints" to their corresponding diploid genotypes. Considering 'Bodegold', registered in 1962 as a tetraploid variety [54], which consisted of di- and tetraploid plants, we hypothesize that contamination with closely related wild growing diploid chamomile through seeds or (unreduced) pollen has led to variable ploidy [19]. Contrarily, 'Camoflora' (a diploid variety) might have experienced fertilization with both unreduced male and female gametes or unreduced egg cells crossed with cultivated tetraploid chamomile, which both could have led to the detection of tetraploid genotypes in our study. However, frequent gene flow between di- and tetraploid chamomile is not expected due to the different ploidy of the gametes, which would typically lead to highly sterile triploid $\mathrm{F}_{1}$-progeny $[55,19]$. Consequently, an increase in the genetic diversity of tetraploid chamomile origins by crosses with diploids is not likely to happen spontaneously, and hence the inclusion of different new origins in breeding programmes would likely be advantageous.

\section{Geographic origin showed no congruence with genetic structure}

In our analysis, there was no clear congruence between the genetic structure (clusters) and geographic origin (Fig. 2 and Additional file 9: Fig. S8b), i.e. no clustering due to geographic origin could be found. Even though the origins from Argentina (010) and North Korea (516) indeed seem to be genetically distinct from the European 
ones (Additional file 9: Fig. S8b), the samples from Russia (23), Egypt (26) and USA (27) showed strong similarity to diverse European origins. An explanation could be that regular exchange of plant material between the regions took place for this mainly outcrossing species, and that in our panel of plants were mainly cultivated chamomile origins with good agricultural performance. Franke and Schilcher [9] discriminated the origin of chamomile flowers by their chemotype, but only from wild and not cultivated collections. For the crop plant Brassica rapa, Tanhuanpää et al. [56] analysed 61 accessions with SNP markers and found grouping corresponding to morphotype and flowering habit, but not to geographic origin. Their results are comparable to our data, indicating the limited value of the geographic origin alone (without correlation to other traits) to genetically structure cultivated outcrossing plants for which the exchange of genetic material is not inhibited. Consequently, only with numerous wild collected samples from the natural regions of origin (e.g. Iran) specific geographic footprints in the genetic patterns might be revealed.

\section{Flowering started earlier for diploid than for tetraploid chamomile plants}

Diploid plants flowered in average significantly earlier than tetraploid ones (Fig. 3, Additional file 10: Table S2), as has been shown for Chamerion angustifolium $[57,58]$. It is hypothesized that (auto-) tetraploid plants develop slower and flower later due to the longer time necessary for replication of a doubled genome [59, 60], which consequently may lead to slowing of metabolism and growth rates in polyploids $[61,62]$. Since tetraploid chamomile is autotetraploid, possible effects of allopolyploidy like allelic interactions or epigenetic modifications of homoeologous loci leading to nonadditive gene regulation [63, 64], are not considered.

The high genomic heritability observed for the flowering time in our study (Fig. 5) additionally indicates a strong genetic influence on the flowering time in chamomile, as has been described for Arabidopsis and Brassica. Mayfield et al. [64] hypothesized that late flowering in these genera is a dominant trait, as flowering time probably depends on the expression of a repressor gene. Thus, late flowering in tetraploids compared to diploids could be additionally influenced by higher chances for dominant alleles to be present. Bao et al. [65] identified factors regulating flowering and endopolyploidization in Arabidopsis and suggest an involvement of cell cycle control in the timing of reproductive transition.

\section{Identification of the flowering time (FT) associated sequences in chamomile can enhance breeding}

The 5 sequences containing the SNPs significantly associated with flowering time (Additional file 12: Table S4) may serve as a starting point to develop molecular markers to be used in marker assisted selection (MAS) for FT in chamomile. Early flowering (=early harvesting) could help circumvent negative effects on yield due to summer drought, whereas late flowering might be of advantage in cold regions with late frost, especially when sowing was already done in autumn. Additionally to the effect of the ploidy on FT, molecular markers could facilitate the breeding for early or late flowering varieties by selecting genotypes with genetic factors for these traits.

The BLAST alignment demonstrated that the orthologue of one of these 5 sequences ("2445"; Additional file 12: Table S4) codes for protein connected to flowering (i.e. self-pollination) in A. thaliana [47]. Further investigations would be required to unravel the function of the identified sequences in chamomile.

High alpha-bisabolol content detected in tetraploid plants from two genetically defined groups indicates its limited occurence in cultivated chamomile

Only 9 chamomile genotypes (origins 'Manzana,' 'Lutea,' 'Goral' and 'Zloty Lan') from 2 STRUCTURE groups (Fig. 2) showed a high content of alpha-bisabolol, as has been described for 'Manzana,' 'Lutea', and 'Goral' [2]. Here, only one out of three analysed 'Goral' genotypes showed a high bisabolol level, while two of three 'Zloty Lan' genotypes were alpha-bisabolol-rich with the third genotype being rich in alpha-bisabolol oxide $\mathrm{B}$, in contrast to the data of Franke and Schilcher [2] and Das [7]. Our data for 'Lazur' also differ from the data of Franke and Schilcher [2] as we detected high levels of bisabolol oxide A and B but no bisabolon. These differences could be explained by genotypic variability in the polymorphic varieties of this outcrossing species, potentially increased by introgression with other chamomile populations during cultivation. This potential variability should be taken into account when maintaining a variety characterized by high-levels of specific compounds serving as medicinal drug, as well as when breeding new varieties.

The pharmaceutically important sesquiterpene alphabisabolol was detected in 28 of the analysed plants. It was previously suggested that an oxidative biosynthetic pathway converts the alpha-bisabolol to bisabolol oxide $\mathrm{B}$ or to bisabolol oxide $\mathrm{A}$, and from the latter further to bisabolone oxide A $[66,67]$.

The 9 alpha-bisabolol rich genotypes belonged to 4 varieties (see above) from 2 different tetraploid groups, both possessing 2 main genetic clusters as defined by STRUCTURE (compare Table 2 and Fig. 2). However, a general conclusion that heterotic effects lead to the higher content of alpha-bisabolol cannot be deduced from our data (Fig. 4 and Fig. 2), as many origins with several main genetic clusters each had no detectable alpha-bisabolol 
content. Since only 2 tetraploid groups showed plants with high alpha-bisabolol content in our study, their membership in two main genetic clusters could also be a random effect explained by a breeding process of choosing different genetic materials as parents, but not necessarily leading to significant heterotic effects. This view is also supported by the analysis of the average heterozygosity. Some alpha-bisabolol rich genotypes displayed an elevated level of heterozygosity over the whole DNA-sequences, but more genotypes with the same level of heterozygosity contained no alpha-bisabolol (Additional file 15: Fig. S9, Additional file 16: Table S7). Wagner et al. [16] describe the inheritance of the ability to produce alpha-bisabolol as monogenic, which does not support the involvement of a heterosis effect in its content. The gene most likely responsible for alpha-bisabolol formation is the alphabisabolol synthase McTPS2 identified in chamomile [68]. The expression of such a terpene synthase was often found to be dominant in many plants including maize $[69,70]$. In a genome wide association study of maize, several SNPs with significance for terpene production were located in terpene synthase genes [71]. However, in chamomile, none of the SNPs associated with alpha- bisabolol content were located in the sequences of alpha-bisabolol synthase or other genes with an apparent involvement in terpene biosynthesis [21]. Some of the SNPs controlling alphabisabolol biosynthesis may affect regulatory factors that also cause a positive introgression/heterosis effect.

It cannot be concluded that tetraploidy leads to an enhanced potential for elevated levels of alpha-bisabolol, since only some tetraploids had high levels of it, and for 'Manzana' the diploid starting material ('Degumille': [53]) is already described to contain high levels of alphabisabolol.

\section{Connection between high alpha-bisabolol content with genes for plant defense and stress response}

Thirteen out of the 60 sequences harbouring the 72 SNPs significantly associated with alpha-bisabolol content could be annotated, 9 of which had orthologues in multiple plant species, of which 4 are described with roles in plant biotic and abiotic stress response (Additional file 13: Table S5).

The association of genes for plant defense and stress response with alpha-bisabolol content is consistent with the antifungal and antibacterial effects of alpha-bisabolol and its oxides [10, 72], which are part of their medical value. Secondary metabolites often function in plant defense and stress response, and in particular, terpenoids (a class of substances to which the bisaboloids belong) play vital roles in plant defense [73]. Furthermore, synthesis and accumulation of natural products (i.e. secondary metabolites) is enhanced in drought-stressed plants, or by application of signal transducers $[74,75]$. Hence, we hypothesize that moderate stress might enhance the production and thus concentration of alpha-bisabolol in chamomile, and yield as long as the overall growth of the plant is not hampered.

\section{Conclusion}

Our analyses of high quality SNPs enabled us to identify genetic clustering in chamomile, with some genotypes belonging mainly to one genetic cluster, while others demonstrate evidence for introgression beween different genetic clusters. Tetraploid varieties tended to be less diverse than the diploid ones. Several origins were identified as being genetically different from most other origins, suggesting their possible use for exploiting heterosis. We identified several genotypes with high levels of the medicinal important substance alpha-bisabolol. Single genotypes tended to be enriched in only one of the four bisaboloids. GWAS identified highly significant $(P<0.01)$ SNPs for flowering time (9) and alpha-bisabolol content (71). The data from GWAS pave the way for future research towards the identification of marker trait associations, their underlying genetics and their use in marker assisted selection (MAS) for practical breeding in German chamomile.

\section{Additional files}

Additional file 1: Figure S1. PCoA analysis of the 95 samples reveals the outgroup $M$. discoidea to be clearly distinct from $M$. recutita. Colours: green: outgroup from M. discoidea (701_01, MD1_04, MD1_05, MD1_06); red: homogenous group of 14 tetraploid origins (007_02, 007_03, 007_04 008_02,008_04, 008_05, 011_01,011_04,011_05, 013_04, 013_06, 014_04, 014_05, 016_02, 016_04, 019_01,019_03,021_02, 021_03, 021_05, 022_01, 022_02, 022_04, 022_06, 023_01,023_02, 023_03, 024_02, 024_03, 024_05, 024_07, 027_02, 027_03, 027_04, 032_01, 032_04, 032_05, 033_03, 033_05); blue: rather diverse group consisting of all remaining samples. Principal coordinate analysis (PCoA, Gower 1966) based on one Euclidean distance matrix termed modified Rogers' distance (mRD, Wright 1978; Goodman and Stuber 1983; Reif et al. 2005) as another presentation of population structure. The specific algorithm was illustrated in Reif et al. 2005. Corresponding programming is executed in R ( $R$ Core Team 2013). References: Goodman M M, Stuber C W. Races of maize. 6: Isozyme variation among races of maize in Bolivia[R]. 1983. Gower JC (1966) Some distance properties of latent root and vector methods used in multivariate analysis. Biometrika. 53(3-4):325-338. R Core Team (2013). $R$ : A language and environment for statistical computing. R Foundation for Statistical Computing, Vienna, Austria. ISBN 3-900,051-07-0, URL http://www.R-project.org/. Reif J C, Melchinger A E, Frisch M. Genetical and mathematical properties of similarity and dissimilarity coefficients applied in plant breeding and seed bank management[J]. Crop Science, 2005, 45(1): 1-7. Wright, S. 1978. Evolution and genetics of populations. Vol. IV. The Univ. of Chicago Press. (DOCX 62 kb)

Additional file 2: Figure S2. STRUCTURE* analysis $(K=4)$ including outgroup M. discoidea (last 4 samples, blue) reveals strict genetic separation from $M$. recutita. ${ }^{*}$ The genotypes are represented by the vertical bars, whereas the different colours indicate the four genetic clusters. (DOCX $48 \mathrm{~kb}$ )

Additional file 3: Figure S3. Calculation of Delta $K$ according to Evanno et al. (2005) by structure harvester for $K=1$ to 15 (Earl and von Holdt 2012; $K=$ number of clusters) determines values of 3 and 7 to fit the data best (DOCX $25 \mathrm{~kb}$ ) 
Additional file 4: Figure S4. STRUCTURE analysis assuming 3 clusters $(K=3) .{ }^{*}$ The genotypes are represented by the vertical bars, whereas the different colours indicate the three genetic clusters (Additional file 5: Table S1). (DOCX 48 kb)

Additional file 5: Table S1. The different genetic clusters $(K=7)$ from the STRUCTURE analysis for the chamomile genotypes. (DOCX $18 \mathrm{~kb}$ )

Additional file 6: Figure S5. STRUCTURE* analysis with allele frequencies assumed to be independent among populations and for 7 clusters (K) leads to low population structure differentiation. ${ }^{*}$ The genotypes are represented by the vertical bars, whereas the different colours indicate the seven genetic clusters. (DOCX $45 \mathrm{~kb}$ )

Additional file 7: Figure S6. Average ploidy level for the groups of plants organized according to their number of main STRUCTURE-clusters (> = 9.5\%). (DOCX $35 \mathrm{~kb})$

Additional file 8: Figure S7. STRUCTURE* analysis assuming 7 clusters $(K=7)$, organized according to Table $2 .{ }^{*}$ The genotypes are represented by the vertical bars and the different origins are separated by vertical black lines, whereas the different colours indicate the seven genetic clusters (Additional file 5: Table S1). The top row indicates the geographical origin (upper) and ploidy (lower) for each sample according to Table 1 (DOCX $516 \mathrm{~kb}$ )

Additional file 9: Figure S8. PCoA analysis of the 91 samples $M$. recutita coloured according to (a) ploidy, (b) geographic origin, (c) flowering time. (a) ploidy. (b) geographic origin. (c) flowering time. PCOA performed as described in Additional file 1: Fig. S1. (a): red: diploid, green: tetraploid (b) code for geographic origin see Table 1 (c) start flowering from days after sowing (DAS): 1 (78 DAS - 107 DAS), 2 (108 DAS - 200 DAS), 3 (201 DAS - 260 DAS), 4 (261 DAS - 298 DAS), 1-2: short day conditions; 3-4: long day conditions. (DOCX $431 \mathrm{~kb})$

Additional file 10: Table S2. Flowering time for diploid and tetraploid chamomile (DOCX $11 \mathrm{~kb}$ )

Additional file 11: Table S3. Genomic heritability: result from analysis 20 times with 5-fold cross validation (DOCX $13 \mathrm{~kb}$ )

Additional file 12: Table S4. Significant SNPs for the traits flowering time (ft, 9 SNPs) and alpha-bisabolol content (bis, 72 SNPs)* . ${ }^{*}$ The SNPs for the traits flowering time (ft, 9 SNPs) and alpha-bisabolol content (bis, 72 SNPs) are contained in 5 and 60 different DNA-sequences, respectively. The sequences in the table are organized according to the $p$-value. ${ }^{*}$ Red letters in the sequence indicate the SNPs identified for this sequence, whereas bold red letters indicate the actual SNP for which the data are given in the corresponding line and for which the other alleles are listed in the fourth column. The single-letter IUPAC nucleotide code is used. (DOCX $23 \mathrm{~kb}$ )

Additional file 13: Table S5. BLAST alignment results* for 5 and 13 sequences harbouring SNPs significantly associated with flowering time (FT) and alpha-bisabolol, respectively. * BLAST alignment results threshold: BLAST-score of $>=80$ with a sequence identity of $>=80 \% / 75 \%$ and an E-value $<1.33 \times 10^{-13}$; (in brackets): results below the threshold (minimum BLAST-score of $>55$ with a sequence identity of $>=75 \%$ and an E-value $<1 \times 10^{-4}$. The blastn algorithm was used for the analysis of the data, since the results obtained from tblastx were similar to the ones from blastn. Tblastx achieved not more hits above the significance threshold than blastn at the NCBI database. ** A more general annotation approach, an HMM (hidden Markov model) search through the Protein families database, did also not yield any results for sequence $6153 .{ }^{* * *}$ tblastx. The BLAST alignment of the 5 sequences harbouring significantly associated SNPS to FT (Additional file 12: Table S4) against the NCBI nucleotide collection of flowering plants identified 2 sequences with significant hits to potential candidate genes in multiple plant species (BLAST-score threshold see above, with a sequence identity of $>=80 \%$ ). Below the significance threshold, for 3 sequences an alignment to plant species could be done, but not for sequence 6153. (1) Jankowsky E. RNA Helicases at work: binding and rearranging. Trends in biochemical sciences. 2011;36(1):19-29. doi:10.1016/ j.tibs.2010.07.008. (2) Kurasawa K, Matsui A, Yokoyama R, Kuriyama T,
Yoshizumi T, Matsui M, Suwabe K, Watanabe M, Nishitani K. The AtXTH28 gene, a xyloglucan endotransglucosylase/hydrolase, is involved in automatic self-pollination in Arabidopsis thaliana. Plant Cell Physiol. 2009; 50(2):413-22. doi: 10.1093/pcp/pcp003. From the above 13 alpha-bisabolol associated sequences, one has been described as microsatellite sequence (1379). For the remaining 12 sequences, specific gene products were described in multiple plant species: "722" ascorbate peroxidase 2-like protein, 3 species; "1139" glutamate receptor, 2 species; "1732" predicted: probable carboxylesterase 6, 5 species; "1998" predicted: nuclear fusion defective 4-like (NFD4; LOC109841189) protein, 2 species; "3218" ammonium transporter 3 member 1-like, 2 species; "3223" U-box domain-containing protein 13 and armadillo/beta-catenin repeat family protein, 3 species; "3249" probable pre-mRNA-splicing factor ATP-dependent RNA helicase, 23 species; "4194" mostly asparagine synthetase, 60 species; "5721" chaperone protein ClpB1/ heat shock protein, 42 species; "6386" lipase, 1 species; "6598" malate dehydrogenase, chloroplastic-like, 19 species; "6654", mainly reticulon-like protein B2, 24 species. (3) Portereiko MF, Sandaklie-Nikolova L, Lloyd A, Dever CA, Otsuga D, Drews GN NUCLEAR FUSION DEFECTIVE1 encodes the Arabidopsis RPL21M protein and is required for karyogamy during female gametophyte development and fertilization. Plant Physiol. 2006; 141:957-965. (4) Caverzan A, Passaia G, Rosa SB, Ribeiro CW, Lazzarotto F, Margis-Pinheiro M. Plant responses to stresses: Role of ascorbate peroxidase in the antioxidant protection. Genetics and Molecular Biology. 2012;35 (4 Suppl):1011-1019. (5) Forde BG, Roberts MR. Glutamate receptor-like channels in plants: a role as amino acid sensors in plant defence? F1000Prime Reports. 2014;6:37. doi:10.12703/P6-37. (6) Sharma M, Pandey A, Pandey GK. $\beta$-catenin in plants and animals: common players but different pathways. Frontiers in Plant Science. 2014;5:143. doi:10.3389/ fpls.2014.00143. (7) Lee U, Rioflorido I, Hong SW, Larkindale J, Waters ER, Vierling E:: 2007. The Arabidopsis ClpB/Hsp100 family of proteins: chaperones for stress and chloroplast development. Plant J. Jan;49(1):115-27 (DOCX 24 kb)

Additional file 14: Table S6. BLAST aligment (megablast) against the sunflower genome (https://www.heliagene.org/HanXRQ-SUNRISE/: Helianthus annuus XRQ genome assembly. The chamomile sequence names in bold letters were aligned by BLAST against NCBI nucleotide collection of flowering plants, and for them gene products were described in multiple plant species above the alignment threshold (Additional file 13: Table S5). (DOCX $23 \mathrm{~kb}$ )

Additional file 15: Figure S9. Alpha-bisabolol in relation to the average heterozygosity for all polymorphic SNPs for the chamomile genotypes. The high alpha-bisabolol rich genotypes displayed an elevated level of heterozygosity, but more genotypes with the same level of heterozygosity contained no alpha-bisabolol $(\mathrm{R} 2=0.056)$. The underlying data are listed in Additional file 16: Table S7. The two datasets used: (1) demultiplexed fasta-file of the barcoded reads for each genotype and (2) the matrix for the filtered 6495 SNPs will be made publicly available after acceptance via e!DAL (http://edal.ipk-gatersleben.de) with a proprietary $\mathrm{DOl}$, and during the revision process sent on request by the corresponding author. (DOCX $55 \mathrm{~kb}$ )

Additional file 16: Table S7. Number of SNPs showing heterozygosity and alpha-bisabolol content for the single chamomile genotypes. ${ }^{1}$ In relation to 44,468 variable sites (polymorphic SNPs) mined by the pyRAD pipeline before filtering. ${ }^{2}$ all values: $\times 10^{6}$ (DOCX $16 \mathrm{~kb}$ )

\section{Acknowledgements}

The authors would like to thank Marlis Sonnenschein from the Pharmaplant $\mathrm{GmbH}$ and Dr. Richard Pickering for the provision of seeds, and Dr. Lyudmyla Malysheva-Otto for her advice concerning the association analysis and reading of the manuscript. We thank the members of the Cornell University Biotechnology Resource Center (BRC) for the practical conduction of the GBS analysis, as well as SUNRISE consortium (funded by the ANR grant ANR-11-BTBR-0005) for the access to the sunflower genome database. We are grateful to the anonymous reviewers for their valuable comments.

\section{Funding}

Parts of this work were financed based upon a resolution of the Federal Parliament of Germany (Deutscher Bundestag) by the Bundesministerium 
für Ernährung und, Landwirtschaft (BMEL, support code 11NR389) via the Fachagentur Nachwachsende Rohstoffe e.V. (FNR) as project executing organisation for the funding programme "Renewable Resources". The funding body did not execute any influence on the study nor the manuscript.

\section{Availability of data and materials}

The datasets used [(1) demultiplexed fasta-file of the barcoded reads for each genotype and (2) the matrix for the filtered 6495 SNPs] are published via e!DAL (Arend et al. 2014, BMC Bioinformatics 15: 214) at (http://dx.doi.org/ 10.5447//PK/2017/7) with the proprietary DOI 10.5447/IPK/2017/7. All other data generated or analysed are included in this manuscript or in its supplementary information files.

\section{Authors' contributions}

TFS and LGO conceived the project. LGO performed the experiments, managed the main data analysis, including GWAS analysis, and wrote the manuscript. HS conducted the PCOA analysis, most of the GWAS and calculated the genomic heritability. JCR significantly contributed to the study design and quantitative analysis of the data. PM performed the GC-MS and analysed the compounds. SP and JD supervised and designed the GC-MS analysis and contributed to study design. JB accomplished the analysis with the pyRAD pipeline and contributed to the analysis of the genetic structure. TFS was a major contributor in designing the study and in writing the manuscript. All authors read and approved the final manuscript.

\section{Ethics approval and consent to participate}

Not applicable.

\section{Consent for publication}

Not applicable.

\section{Competing interests}

The authors declare that they have no competing interests.

\section{Publisher's Note}

Springer Nature remains neutral with regard to jurisdictional claims in published maps and institutional affiliations.

\section{Author details}

${ }^{1}$ Apomixis Research Group, Department Plant Breeding Research, Leibniz Institute of Plant Genetics and Crop Plant Research (IPK), Corrensstrasse 3, D-06466 Seeland OT Gatersleben, Germany. ${ }^{2}$ Research Group of Pharmaceutical Biotechnology, Institute of Pharmacy, Martin-Luther University Halle-Wittenberg, Hoher Weg 8, 06120 Halle (Saale), Germany. ${ }^{3}$ Quantitative Genetics Research Group, Department Plant Breeding Research, Leibniz Institute of Plant Genetics and Crop Plant Research (IPK), Corrensstrasse 3, D-06466 Seeland OT Gatersleben, Germany. ${ }^{4}$ Global Institute for Food Security, University of Saskatchewan, 110 Gymnasium Place, Saskatoon, SK S7N 4J8, Canada.

\section{Received: 13 April 2017 Accepted: 1 August 2017}

\section{Published online: 10 August 2017}

\section{References}

1. Franke $\mathrm{R}$, Schilcher $\mathrm{H}$. Relevance and use of chamomile (Matricaria recutita L.) Acta Hortic. 2007;749:29-43. http://dx.doi.org/10.17660/ActaHortic.2007.749.2

2. Franke $\mathrm{R}$, Schilcher $\mathrm{H}$, editors. Chamomile: industrial profiles. Boca Raton: CRC Press Taylor and Francis Group; 2005.

3. Massoud H. Quantitative Vererbung einiger Ertragsmerkmale und der Hauptkomponenten des ätherischen Öls von Kamille, Matricaria chamomilla L. (syn. Chamomilla recutita L.). Munich: Dissertation, Technische Universität München; 1988.

4. Letchamo W. Ökologische, genetische und ontogenetische Einflüsse auf Wachstum, Ertrag und Wirkstoffgehalt von diploiden und tetraploiden Kamillen, Chamomilla recutita (L.), RAUSCHERT. Giessen: Dissertation, Justus-Liebig-Universität Gießen; 1992.

5. Plescher, A. and M. Sonnenschein, 2013: Züchtung eines Qualitätssorte von Kamille mit hoher Ertragsfähigkeit bei maschineller Ernte (Phase I). Abschlussbericht Demonstrationsprojekt Arzneipflanzen (KAMEL), FKZ 08NR206 Fachagentur Nachwachsende Rohstoffe.
6. Seidler-Lozykowska K. Determination of the ploidy level in chamomile (Chamomilla Recutita (L.) Rausch.) strains rich in alpha-bisabolol. J Appl Genet. 2003:44(2):151-5.

7. Das M. Chamomile: medicinal, biochemical, and agricultural aspects. Boca Raton: CRC Press Taylor and Francis Group; 2015.

8. Wagner C, Friedt W, Marquard RA, Ordon F. Molecular analysis on the genetic diversity and inheritance of (-)-alpha-bisabolol and chamazulene content in tetraploid chamomile (Chamomilla Recutita (L.) Rauschert). Plant Sci. 2005;169:917-27.

9. Pirkhezri M, Hassani ME, Hadian J. Genetic diversity in different populations of Matricaria chamomilla L. growing in southwest of Iran, based on morphological and RAPD markers. Res J Med Plant. 2010;4:1-13.

10. Okoń S, Surmacz-Magdziak A, Paczos-Grzęda A. Genetic diversity among cultivated and wild chamomile germplasm based on ISSR analysis. Acta Sci Pol, Hortorum Cultus. 2013;12(2):43-50.

11. Kilian B, Graner A. NGS technologies for analyzing germplasm diversity in genebanks. Brief Funct Genomics. 2012;11(1):38-50. doi:10.1093/bfgp/elr046.

12. He J, Zhao X, Laroche A, Lu Z-X, Liu H, Li Z. Genotyping-by-sequencing (GBS), an ultimate marker-assisted selection (MAS) tool to accelerate plant breeding. Front Plant Sci. 2014;5:484. http://doi.org/10.3389/fpls. 2014.00484

13. Elshire RJ, Glaubitz JC, Sun Q, Poland JA, Kawamoto K, Buckler ES, Mitchell SE. A robust, simple genotyping-by-sequencing (GBS) approach for high diversity species. PLoS One. 2011;6(5):e19379. doi:10.1371/journal.pone.0019379.

14. Uitdewilligen JGAML, Wolters A-MA, D'hoop BB, Borm TJA, Visser RGF, van Eck HJ. A next-generation sequencing method for genotyping-bysequencing of highly heterozygous Autotetraploid potato. PLoS One. 2013;8(5):e62355. doi:10.1371/journal.pone.0062355.

15. Lu F, Lipka AE, Glaubitz J, Elshire R, Cherney JH, Casler MD, Buckler ES, Costich DE. Switchgrass genomic diversity, Ploidy, and evolution: novel insights from a network-based SNP discovery protocol. PLOS Genet. 2013;9(1):e1003215. doi:10.1371/journal.pgen.1003215.

16. Huang Y-F, Poland JA, Wight CP, Jackson EW, Tinker NA. Using genotypingby-sequencing (GBS) for genomic discovery in cultivated oat. PLoS One. 2014;9(7):e102448. doi:10.1371/journal.pone.0102448.

17. Li H, Vikram P, Singh RP, Kilian A, Carling J, Song J, Burgueno-Ferreira JA, Bhavani S, Huerta-Espino J, Payne T, Sehgal D, Peter Wenzl P, Singh S. A high density GBS map of bread wheat and its application for dissecting complex disease resistance traits. BMC Genomics. 2015;16(1):216. doi:10. 1186/s12864-015-1424-5.

18. Scheben A, Batley J, Edwards D. Genotyping by sequencing approaches to characterise crop genomes: choosing the right tool for the right application. Plant Biotechnol J 2016; http://dx.doi.org/10.1111/pbi.12645.

19. Otto L-G, Junghanns WR, Plescher A, Sonnenschein M, Sharbel T. Towards breeding of triploid chamomile (Matricaria recutita L.) - Ploidy variation within German chamomile of various origins (varieties, populations and accessions). Plant Breed J. 2015;134:485-93.

20. Köllner TG, Schnee C, Gershenzon J, Degenhardt J. The sesquiterpene hydrocarbons of maize (Zea mays) form five groups with distinct developmental and organ-specific distributions. Phytochemistry. 2004;65:1895-902.

21. Irmisch S, Krause ST, Kunert G, Gershenzon J, Degenhardt J, Köllner TG. The organ-specific expression of terpene synthase genes contributes to the terpene hydrocarbon composition of chamomile essential oils. BMC Plant Biol. 2012;12:84. doi:10.1186/1471-2229-12-84.

22. Adams RP. Identification of essential oil components by gas chromatography / mass spectrometry. 4th ed. Illinois: Allured Publishing corporation; 2007. p. 509-24. 614

23. Eaton DAR. PyRAD: assembly of de novo RADseq loci for phylogenetic analyses. Bioinformatics. 2014;30(13):1844-9. doi:10.1093/bioinformatics/btu121.

24. Pritchard JK, Stephens M, Donnelly P. Inference of population structure using multilocus genotype data. Genetics. 2000;155:945-59.

25. Falush D, Stephens M, Pritchard JK. Inference of population structure: extensions to linked loci and correlated allele frequencies. Genetics. 2003;164:1567-87.

26. Hubisz M, Falush D, Stephens M, Pritchard J. Inferring weak population structure with the assistance of sample group information. Mol Ecol Resour. 2009;9(5):1322-32.

27. Evanno G, Regnaut S, Goudet J. Detecting the number of clusters of individuals using the software STRUCTURE: a simulation study. Mol Ecol. 2005; 14:2611-20. 
28. Earl DA. vonHoldt BM. STRUCTURE HARVESTER: a website and program for visualizing STRUCTURE output and implementing the Evanno method. Conserv Genet Resour. 2012:4(2):359-61.

29. Jakobsson M, Rosenberg NA. CLUMPP: a cluster matching and permutation program for dealing with label switching and multimodality in analysis of population structure. Bioinformatics. 2007;23(14):1801-6.

30. Saitou N, Nei M. The neighbor-joining method: a new method for reconstructing phylogenetic trees. Mol Biol Evol. 1987;4(4):406-25.

31. Kearse M, Moir R, Wilson A, Stones-Havas S, Cheung M, Sturrock S, Buxton S, Cooper A, Markowitz S, Duran C, Thierer T, Ashton B, Mentjies P, Drummond A. Geneious basic: an integrated and extendable desktop software platform for the organization and analysis of sequence data. Bioinformatics. 2012;28(12):1647-9.

32. Breiman L. Random forests. Mach Learn. 2001;45(1):5-32.

33. Stekhoven DJ, Buehlmann P. MissForest - nonparametric missing value imputation for mixed-type data. Bioinformatics. 2012;28(1):112-8. doi:10.1093/bioinformatics/btr597.

34. Howie B, Fuchsberger C, Stephens M, Marchini J, Abecasis GR. Fast and accurate genotype imputation in genome-wide association studies through pre-phasing. Nat Genet. 2012;44(8):955-9.

35. Rauch A, Kutalik Z, Descombes P, Cai T, Di lulio J, Mueller T, Bochud M, Battegay M, Bernasconi E, Borovicka J, Colombo S, Cerny A, Dufour JF, Furrer H, Günthard HF, Heim M, Hirschel B, Malinverni R, Moradpour D, Müllhaupt B, Witteck A, Beckmann JS, Berg T, Bergmann S, Negro F, Telenti A, Bochud PY. Swiss hepatitis C cohort study; Swiss HIV cohort study. Genetic variation in IL28B is associated with chronic hepatitis C and treatment failure: a genome-wide association study. Gastroenterology. 2010;138(4):1338-45.

36. de los Campos G, Sorensen D, Gianola D. Genomic heritability: what is it? PLoS Genet. 2015;11(5):e1005048.

37. Visscher PM, Hill WG, Wray NR. Heritability in the genomics era-concepts and misconceptions. Nat Rev Genet. 2008;9:255-66. doi:10.1038/nrg2322. pmid: 18319743

38. Endelman JB. Ridge regression and other kernels for genomic selection with $R$ package rrBLUP. Plant Genome. 2011;4:250-5. doi:10.3835/plantgenome2011. 08.0024 .

39. VanRaden PM. Efficient methods to compute genomic predictions. J Dairy Sci. 2008:91:4414-23.

40. Altschul SF, Madden TL, Schäffer AA, Zhang J, Zhang Z, Miller W, Lipman DJ. Gapped BLAST and PSI-BLAST: a new generation of protein database search programs. Nucleic Acids Res. 1997;25(17):3389-402.

41. Zhang Z, Schwartz S, Wagner L, Miller W. A greedy algorithm for aligning DNA sequences. J Comput Biol. 2000;7(1-2):203-14.

42. Conesa A, Götz S, Garcia-Gomez JM, Terol J, Talon M, Robles M. Blast2GO: a universal tool for annotation, visualization and analysis in functional genomics research. Bioinformatics. 2005;21:3674-6.

43. Conesa A, Götz S. Blast2GO: a comprehensive suite for functional analysis in plant genomics. International Journal of Plant Genomics. 2008:1-13.

44. Götz S, García-Gómez JM, Terol J, Williams TD, Nagaraj SH, Nueda MJ, Robles M, Talón M, Dopazo J, Conesa A. High-throughput functional annotation and data mining with the Blast2GO suite. Nucleic Acids Res. 2008;36(10):3420-35.

45. Götz S, Arnold R, Sebastián-León P, Martín-Rodríquez S, Tischler P, Jehl MA Dopazo J, Rattei T, Conesa A. B2G-FAR, a species centered GO annotation repository. Bioinformatics. 2011;27(7):919-24

46. https://www.heliagene.org/HanXRQ-SUNRISE/. INRA, SUNRISE consortium: SUNflower Resources to Improve yield Stability in a changing Environment. Helianthus annuus XRQ genome assembly v1r1. Accessed Dec 2016.

47. Kurasawa K, Matsui A, Yokoyama R, Kuriyama T, Yoshizumi T, Matsui M, Suwabe K, Watanabe M, Nishitani K. The AtXTH28 gene, a xyloglucan endotransglucosylase/ hydrolase, is involved in automatic self-pollination in Arabidopsis thaliana. Plant Cell Physiol. 2009;50(2):413-22. doi:10.1093/pcp/pcp003.

48. Sharma M, Pandey A, Pandey GK. $\beta$-catenin in plants and animals: common players but different pathways. Front Plant Sci 2014; 5:143. doi:10.3389/fpls. 2014.00143.

49. Caverzan A, Passaia G, Rosa SB, Ribeiro CW, Lazzarotto F, Margis-Pinheiro M. Plant responses to stresses: role of ascorbate peroxidase in the antioxidant protection. Genet Mol Biol. 2012;35(4):1011-9.

50. Forde BG, Roberts MR. Glutamate receptor-like channels in plants: a role as amino acid sensors in plant defence? F1000Prime Reports. 2014;6:37. doi:10.12703/P6-37.
51. Lee U, Rioflorido I, Hong SW, Larkindale J, Waters ER, Vierling E. The Arabidopsis ClpB/Hsp100 family of proteins: chaperones for stress and chloroplast development. Plant J. 2007;49(1):115-27.

52. Portereiko MF, Sandaklie-Nikolova L, Lloyd A, Dever CA, Otsuga D, Drews GN. NUCLEAR FUSION DEFECTIVE1 encodes the Arabidopsis RPL21M protein and is required for karyogamy during female gametophyte development and fertilization. Plant Physiol. 2006;141:957-65.

53. Franz C, Isaac O. Tetraploid, bisabolol rich chamomile, (Degussa A.-G) Ger. Offen. DE 3,542,756 (CL.A01H1/08), June 26, 1986. DE Appl. 3,446,216, Dec 19; 1984. p. 64.

54. Bundessortenamt. Beschreibende Sortenliste Arznei- und Gewürzpflanzen. http://www.bundessortenamt.de/internet30/fileadmin/Files/PDF/bsl_arznei_ 2002.pdf. 2002; 80-88.

55. Otto SP, Whitton J. Polyploid incidence and evolution. Annu Rev Genet 2000;34:401-37.

56. Tanhuanpää P, Erkkilä M, Tenhola-Roininen T, Tanskanen J, Manninen O. SNP diversity within and among Brassica rapa accessions reveals no geographic differentiation. Genome. 2016;59(1):11-21. doi:10.1139/gen-2015-0118.

57. Levin D. Polyploidy and novelty in flowering plants. Am Nat. 1983;122:1-25.

58. Husband BC. Polyploidy and plant adaptation: a framework for future research. In: Cronk QCB, Whitton J, Ree RH, Taylor IEP, editors. Plant adaptation: molecular genetics and ecology 2004. Proceedings of an international workshop held December 11-13, 2002, Vancover, British Columbia, Canada. Ottawa: NRC Research Press. p. 119-26.

59. Bennett MD, Leitch IJ. Genome size evolution in plants. In: Gregory TR, editor. The evolution of the genome. Amsterdam: Elsevier Academic Press; 2005. p. 89-162.

60. Vichiato MRdeM, Vichiato M, Pasqual M, Rodrigues FA, de Castro DM. Morphological effects of induced polyploidy in Dendrobium Nobile Lindl. (Orchidaceae). Crop Breeding and Applied Biotechnology 2014; 14(3):154-159. https://dx.doi.org/10.1590/1984-70332014v14n3a23.

61. Cavalier-Smith T. Nuclear volume control by nucleoskeletal DNA, selection for cell volume and cell growth rate, and the solution of the DNA C-value paradox. J Cell Sci. 1978;34:247-78.

62. te Beest M, Le Roux JJ, Richardson DM, Brysting AK, Suda J, Kubesova M, Pysekte $P$. The more the better? The role of polyploidy in facilitating plant invasions. Ann Bot. 2012;109(1):19-45. doi:10.1093/aob/mcr277.

63. Chen JZ, Ni Z. Mechanisms of genomic rearrangements and gene expression changes in plant polyploids. BioEssays : news and reviews in molecular, cellular and developmental biology. 2006;28(3):240-52. doi:10.1002/bies.20374

64. Mayfield D, Chen ZJ, Pires JC. Epigenetic regulation of flowering time in polyploids. Curr Opin Plant Biol. 2011;14(2):174-8. doi:10.1016/j.pbi.2011.03.008.

65. Bao Z, Zhang N, Hua J. Endopolyploidization and flowering time are antagonistically regulated by checkpoint component MAD1 and immunity modulator MOS1. Nat Commun. 2014;5:5628. doi:10.1038/ncomms6628.

66. Franz C, Wickel I. Zur Vererbung der Bestandteile des Kamillenöls, 1. Mitt:: Qualitative Vererbung von Chamazulen und Bisabolol. Herba Hung. 1985;24(2-3):49-59

67. Horn W, Franz C, Wickel I. Zur Genetik der Bisaboloide bei der Kamille. Plant Breed. 1988;101:307-12.

68. Zhu L, Xu F, Tao T, Liu X, Song Q, Chang J, Zhang W. Isolation and sequence analysis of a Terpene Synthase (MCTPS2) gene from Matricaria Chamomilla. Int J Curr Res Biosci Plantbiol. 2015;2(9):84-9.

69. Köllner T, Schnee C, Gershenzon J, Degenhardt J. The variability of sesquiterpenes emitted from two Zea mays cultivars is controlled by allelic variation of two terpene synthase genes encoding stereoselective multiple product enzymes. Plant Cell. 2004;16(5):1115-31. doi:10.1105/tpc.019877.

70. Köllner TG, Held M, Lenk C, Hiltpold I, Turlings TCJ, Gershenzon J, Degenhardt J. A maize ( $E$ )- $\beta$-caryophyllene synthase implicated in indirect defense responses against herbivores is not expressed in most American maize varieties. Plant Cell. 2008:20:482-94.

71. Richter A, Schaff C, Zhang Z, Lipka AE, Tian F, Köllner TG, Schnee C, Preiß S, Irmisch S, Jander G, Boland W, Gershenzon J, Buckler ES, Jörg DJ. Characterization of biosynthetic pathways for the production of the volatile homoterpenes DMNT and TMTT in Zea mays. Plant Cell. 2016; doi:10.1105/tpc.15.00919.

72. Kamatou GPP, Viljoen AM. A review of the application and pharmacological properties of a-Bisabolol and a-Bisabolol-rich oils. J Am Oil Chem Soc. 2010;87(1):1-7.

73. Gershenzon J, Dudareva N. The function of terpene natural products in the natural world. Nat Chem Biol. 2007;3:409-14. 
74. Kleinwächter M, Selmar D. New insights explain that drought stress enhances the quality of spice and medicinal plants: potential applications. Agron Sustain Dev. 2015;35:121-31. doi:10.1007/s13593-014-0260-3.

75. Kleinwächter M, Paulsen J, Bloem E, Schnug E, Selmar D. Moderate drought and signal transducer induced biosynthesis of relevant secondary metabolites in thyme (Thymus vulgaris), greater celandine (Chelidonium majus) and parsley (Petroselinum crispum). Ind Crop Prod. 2015;64:158-66.

76. Kottek M, Grieser J, Beck C, Rudolf B, Rubel F. World map of the Köppen-Geiger climate classification updated. Meteorol Z. 2006;15(3):259-63.

Submit your next manuscript to BioMed Central and we will help you at every step:

- We accept pre-submission inquiries

- Our selector tool helps you to find the most relevant journal

- We provide round the clock customer support

- Convenient online submission

- Thorough peer review

- Inclusion in PubMed and all major indexing services

- Maximum visibility for your research

Submit your manuscript at www.biomedcentral.com/submit
Biomed Central 